\title{
Bioloid robot and Kinect to motivate physical activation in children
}

\author{
Michel García ${ }^{1}$, Cinhtia González ${ }^{1}$, Sergio González ${ }^{1}$, Neyfis Solís ${ }^{1}$
}

Faculty of Mathematics, University Autonomous of Yucatán, Tizimín, Yucatán, México ${ }^{1}$

\begin{abstract}
This research presents a contribution to the reduction of the problem of childhood obesity that affects the health of children and young people worldwide, causing negative consequences in the personal and family life of future affected adults. A playful application is described, developed using a Bioloid robot and a Kinect device, in order to incorporate the benefits of video games in the performance of activities and movements that on a daily basis could be tedious. With the developed application it is possible to identify points and joints of the human body and the movements of a person, which allows interaction in a playful environment, where the user imitates the movements of physical activation performed by the Bioloid robot and captured by the Kinect sensor.
\end{abstract}

Keywords: Physical activation, Bioloid robot, Kinect, Child health, Playful software.

\section{INTRODUCTION}

Obesity and overweight are two types of malnutrition that afflict the population of the world, but especially children, to the extent that it has been considered the new pandemic [1]. The main causes of these problems are the bad eating habits that children acquire at home and that, if not corrected, can bring bad consequences in the future [2]. According to data from the World Health Organization [3], 45\% of child deaths are associated with malnutrition. 52 million children under five years of age show signs of emaciation, 17 million suffer from severe emaciation, and 155 million are underweight, while 41 million are overweight or obese.

In Mexico, the National Health and Nutrition Survey 2020 reveals that in this our country the prevalence of overweight falls more strongly on children under 8 years of age, being $24 \%$ of them, and $26 \%$ with obesity in children under 9 years of age [4], in addition to the fact that in recent years our country has been ranked among the first places of the world prevalence of obesity in the adult population.

According to studies, there are factors that restrict the emergence and increase of obesity in population; among these factors are genetics, age, sleep and medication, bottle versus breastfeeding, comforts, and social relationships, as well as health behaviours such as eating patterns, levels of physical activity and time in front of the television. In addition to individual traits and behaviours, the recent increase in obesity can be attributed to societal changes in eating habits, food and beverage availability, and sedentary lifestyle, which has shifted the balance of energy intake and expenditure [5]

There are few studies in the literature related to the use of robots and Kinect devices, such as the one presented by Corina y Scassellati [6], who explain the use of social robots to promote physical activity for adolescents, as well as to maintain their motivation to achieve goals. There is also the VITA interface [7] that offers virtual therapies based on motion capture through Kinect and aims to make the physical therapies recommended by specialists' fun for people.

In this sense, it has been shown that the use of social robots can help children to cope with problems such as obesity, diabetes, and autism, since these perform tests and games that allow children to understand their condition and strengthen their confidence. For example, social robots serve as a tool that allows children to stay engaged and motivated to perform activities that improve their physical condition and reduce problems related to sedentary lifestyles $[8,9]$.

\section{MATERIALS AND MethodS}

This research has an experimental design, with a quantitative methodology of descriptive type. The development of the prototype is described below.

\section{A. Components of the Xbox 360 Kinect Sensor}

The Kinect device was initially intended as a game controller but turned out to be able to capture the human skeleton, recognize it and position it in the plane thanks to the components that integrate it, such as the depth sensor, RGB camera, matrix of four microphones, and the infrared sensor of the sender and receiver. These features allow the device to be used 


\section{International Advanced Research Journal in Science, Engineering and Technology \\ Impact Factor 7.105 $\div$ Vol. 9, Issue 2, February 2022 \\ DOI: 10.17148/IARJSET.2022.9209}

to program applications that allow interaction with virtual elements through movements of the human body. Complementing the hardware, the Kinect for Windows Software Development Kit (SDK) is a library that provides different code functions that help to interact with the Kinect device; allowing to obtain information about the different skeletons and their joints as shown in Fig. 1.

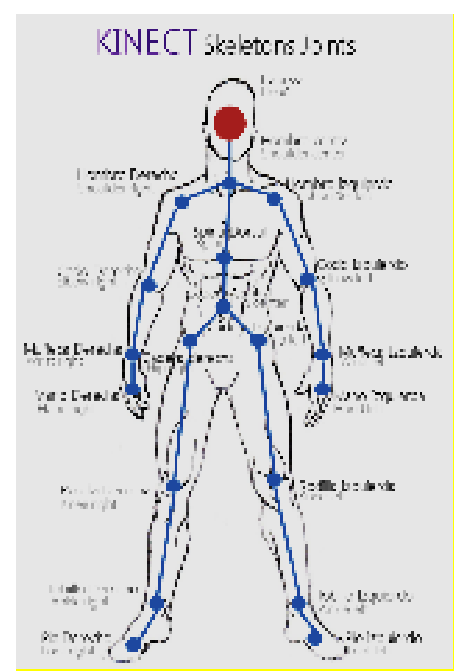

Fig. 1 Components of the Xbox 360 Kinect sensor: Localization of joints.

Once the Kinect detects a human skeleton, it is able to provide detailed information about the exact position in the plane $(\mathrm{X}, \mathrm{Y}, \mathrm{Z})$ of all the joints of that human skeleton. With this information, it is possible to develop applications that work with the interaction of the human body, without the need for keyboards, mice or touchpads [10].

B. Skeleton tracking

Kinect skeleton tracking is used to recognize people and track their actions. To recognize a user only requires being in front of the sensor, making sure that the sensor can see the head and upper body of the user. Recognition allows a standing or sitting position, although side postures provide some challenges in terms of the part of the user that is not visible to the sensor, as shown in Fig. 2.

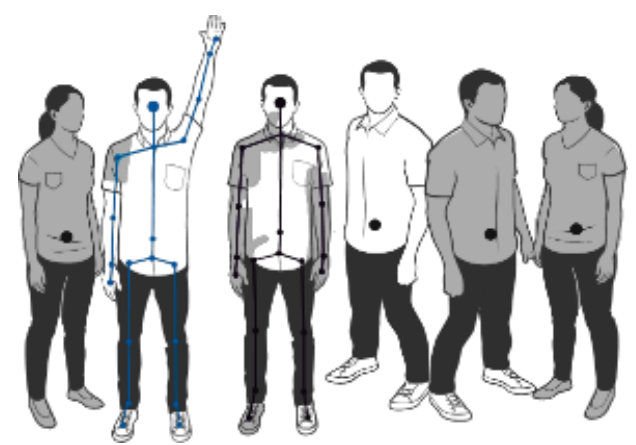

Fig. 2 Skeleton tracking: user recognition.

\section{Bioloid robot}

On the other hand, the Bioloid robot is a miniature humanoid with general movements of the pelvis, foot, arms and head, which has been used by the scientific community. The intended applications for humanoid robots involve extensive interaction with humans in their natural environments [11].

The Bioloid Premium robot of the company ROBOTIS, has a series of sensors such as the gyroscope, IR and the distance meter, in addition to its design allowing the construction of different types of robots such as the humanoid, scorpion, spider, dinosaur, and dog. The model used in the described work is the Bioloid Premium Robot Type C (Fig. 3) 


\section{International Advanced Research Journal in Science, Engineering and Technology \\ Impact Factor 7.105 $\div$ Vol. 9, Issue 2, February 2022 \\ DOI: 10.17148/IARJSET.2022.9209}

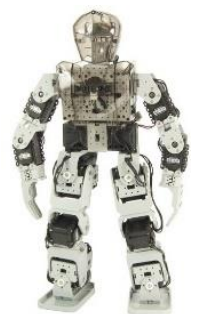

Fig. 3 Bioloid Premium Robot Type C.

Some of the components contained in the Bioloid robot:

- Main Controller CM-530 (ARM Cortex M3 / 32bit).

- DYNAMIXEL AX-12A (exclusive servomotor of the robot).

- 2-axis gyroscope $\mathrm{X}, \mathrm{Y}$.

- Distance Sensor.

- Infrared (IR) Sensor.

- RC-100A (Remote Control).

- $\quad$ LiPo Battery $(11.1 \mathrm{~V}, 1000 \mathrm{mAh} / \mathrm{PCM})$.

\section{Kinect-Bioloid Robot connection}

For this project, an interface to connect the Kinect to the robot was developed with the Visual Basic 2012 programming language. This allowed the reading of the data of the skeleton of the robot, and the detection of the points that represent the body parts of the user. This information detected by the Kinect is sent to the interface, which in turn sends it to the robot so that it can take the appropriate position Likewise, the RoboPlus Motion and RoboPlus Task programs are used to perform the routines of the Bioloid robot.

\section{E. Application development}

For the realization of this project, it was used a Kinect for Xbox 360 and a PC with Windows 10, and for this configuration it was necessary to use an SDK compatible, which was the Kinect for Windows SDK version 1.5. In the same way, the Visual Basic 2012 programming language was selected to use the SDK and the Kinect, obtaining from the very function of the device the points of the skeleton, as shown in Fig. 4; the latter is possible to be detected by having a person in front of the Kinect, which detects the different points corresponding to the joints of the user.

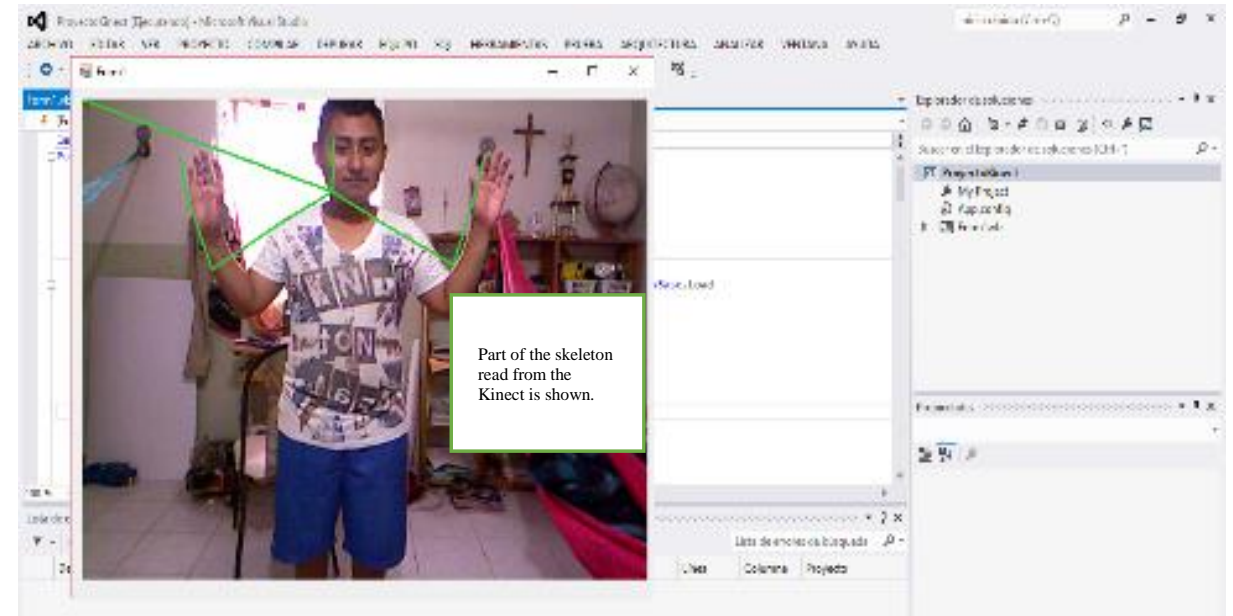

Fig. 4 Kinect programming interface in Visual Basic 2012.

\section{F. RoboPlus Motion}

The RoboPlus program in its RoboPlus Motion option was used to control the positions of the Bioloid robot (Fig. 5), so that it could perform the different movements necessary to carry out the physical activation. The robot includes the necessary routines to perform its own movements, some of which are to move its arms and legs, which allows to program 


\section{International Advanced Research Journal in Science, Engineering and Technology \\ Impact Factor 7.105 $\div$ Vol. 9, Issue 2, February 2022}

DOI: 10.17148/IARJSET.2022.9209

and show to the children a routine performed by the robot, with the purpose of guiding them to imitate the movements presented by the robot.

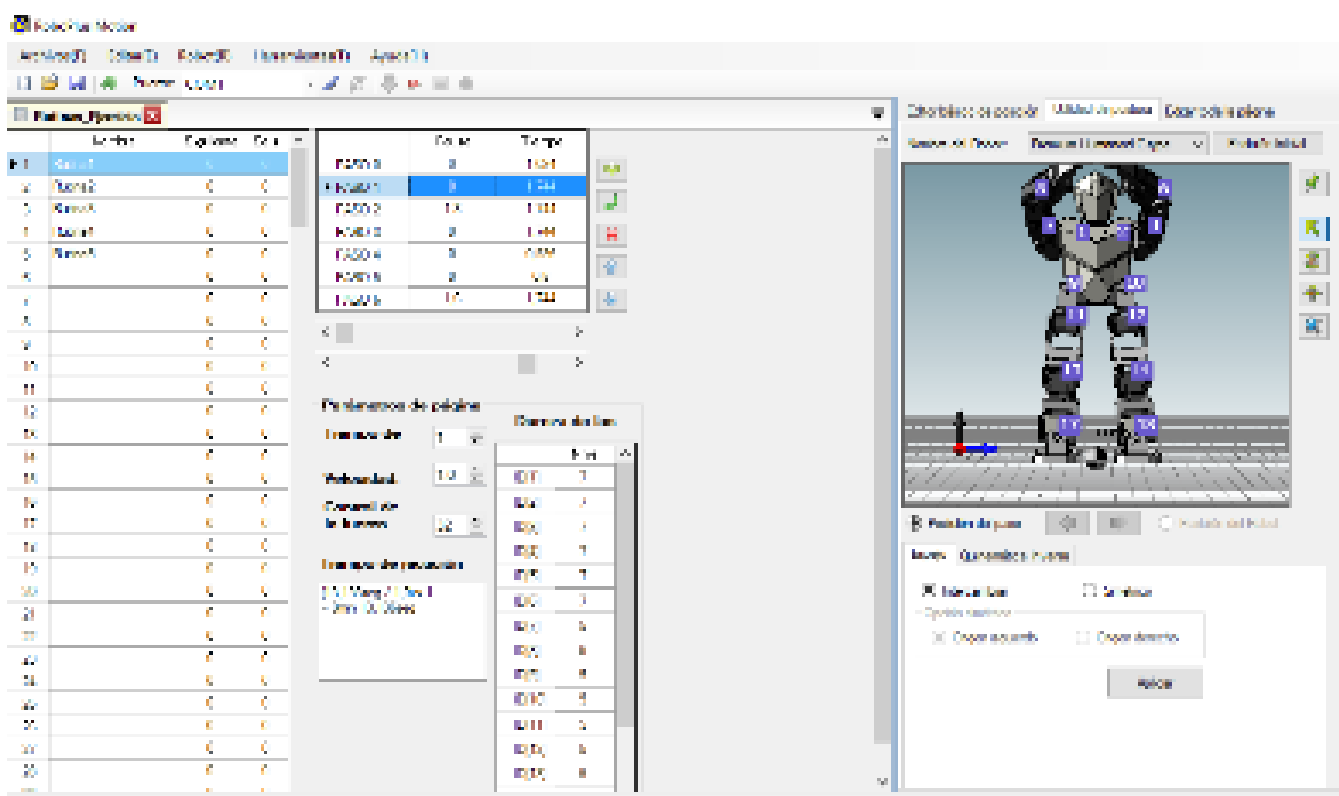

Fig. 5 Programming interface of RoboPlus Motion.

As shown in Fig. 6, the RoboPlus Task option, which is responsible for managing the logic of the robot, was used to choose between its mobility options, and that, by reading the Kinect data, these can be sent to the robot so that it imitates the positions executed by the trainer that are detected by the Kinect. The first tests were carried out with a group of basic education students, who imitated the movements of the robot in a playful and fun environment.

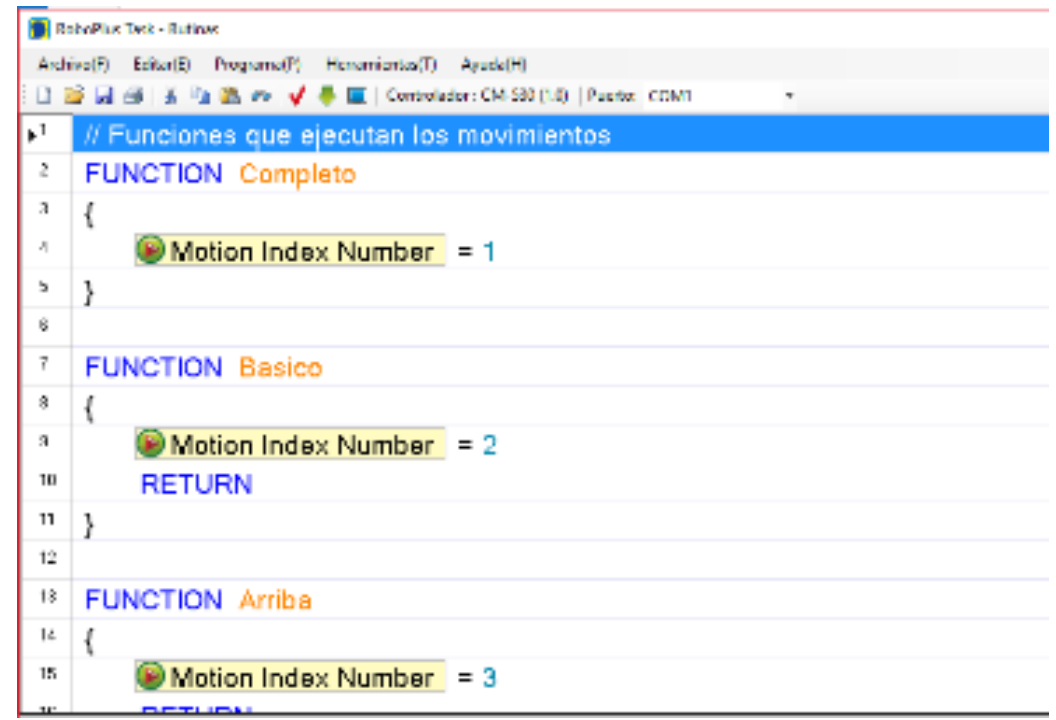

Fig. 6 Programming interface Roboplus Task

Finally, Fig. 8 shows a group of students imitating the movements of the robot during the physical activation session. 


\section{International Advanced Research Journal in Science, Engineering and Technology \\ Impact Factor 7.105 ㄷ Vol. 9, Issue 2, February 2022}

DOI: 10.17148/IARJSET.2022.9209

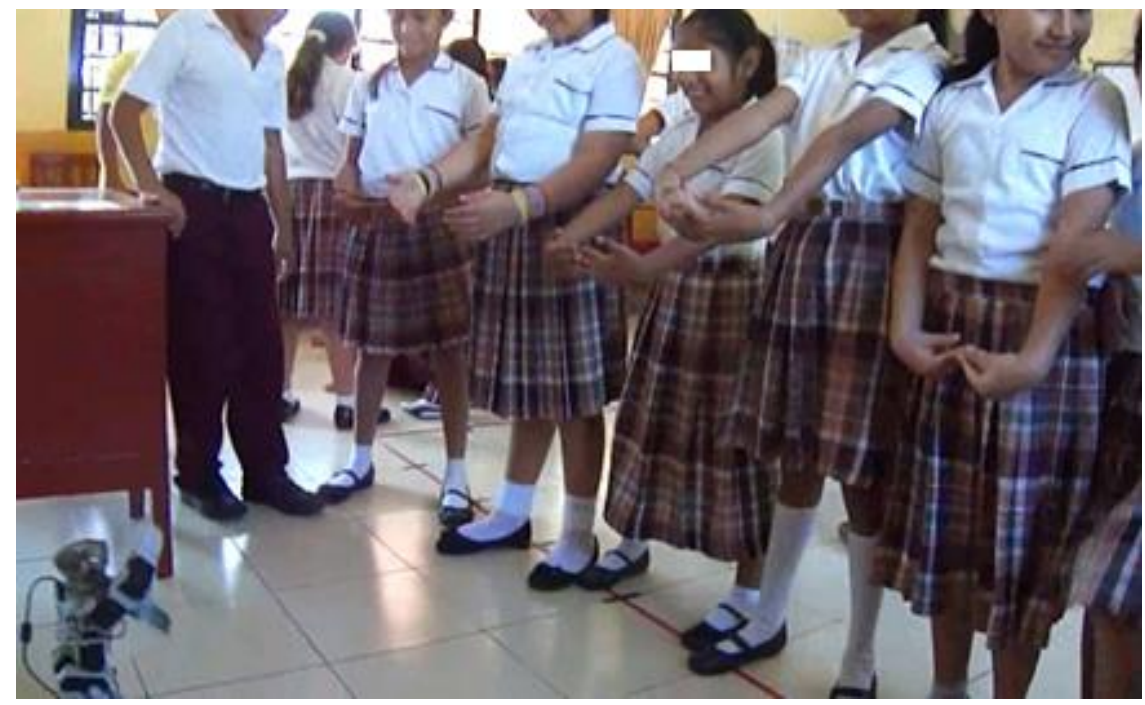

Fig. 7 Students imitating the movements of the Bioloid Premium Robot.

\section{CONCLUSION}

With the presented application, it is intended to contribute to the reduction of cases of childhood obesity so that children give greater importance to the needs of their body for the benefit of their own health, such as performing physical exercise appropriate for their age.

As future work, it is intended to provide the application to a group of children and young people, who will interact with the robot and the Kinect device, performing some physical activation sessions in which the "Bioloid" robot is used as an instructor to motivate them; at the end of these sessions the acceptance of the children towards the robot as an instructor will be measured.

Technological methods are an option to try to prevent the increase in cases of overweight and obese children since these methods are attractive to children. This application is intended to motivate children to perform physical activities with the advice of a robot that is programmed with the appropriate movements for this age group so that children can perform exercises in a fun and safe way.

\section{ACKNOWLEDGMENT}

We thank the Autonomous University of Yucatán and the Faculty of Mathematics from all facilities in the accomplishment of this work.

\section{REFERENCES}

[1]. Shamah Levy, T.: Encuesta Nacional de Salud y Nutrición ENSANUT 2020, COVID-19, 2021.

[2]. Save the Children en México: El estado de la nutrición infantil en México, https://blog.savethechildren.mx/2021/07/06/estado-nutricion-infantil-en-mexico/.

[3]. Organización Mundial de la Salud: Alimentación del lactante y del niño pequeño, https://www.who.int/es/newsroom/fact-sheets/detail/infant-and-young-child-feeding.

[4]. Gobierno de México: Obesidad infantil: Nuestra nueva pandemia, https://www.gob.mx/promosalud/es/articulos/obesidad-infantil-nuestra-nueva-pandemia?idiom=es.

[5]. Smith, J.D., Fu, E., Kobayashi, M.A.: Prevention and Management of Childhood Obesity and Its Psychological and Health Comorbidities. Annu. Rev. Clin. Psychol. 16, 351-378 (2020). https://doi.org/10.1146/annurev-clinpsy100219-060201.

[6]. Corina Grigore, E., Scassellati, B.: Maintaining Engagement in Shared Goals with a Personal Robot Companion through Motivational State Modeling. In: Proceedings of the Human-Robot Teaming Workshop (2015).

[7]. Montoya, A., Orejuela, D.: Interfaz de apoyo para la rehabilitación física de personas con osteoartrosis de rodilla por obesidad en un sistema integral para una continuidad del tratamiento, https://repository.icesi.edu.co/biblioteca_digital/bitstream/10906/76633/1/vita_interfaz_apoyo.pdf, (2013). 
[8]. Nasir, J., Bruno, B., Chetouani, M., Dillenbourg, P.: What if Social Robots Look for Productive Engagement?: Automated Assessment of Goal-Centric Engagement in Learning Applications. Int. J. Soc. Robot. 14, (2022). https://doi.org/10.1007/s12369-021-00766-w.

[9]. Williams, A.: Social robots helping children with diabetes, http://phys.org/news/2014-11-social-robots-childrendiabetes.html.

[10]. Microsoft: About Azure Kinect Sensor SDK, https://docs.microsoft.com/en-us/azure/kinect-dk/about-sensor-sdk.

[11]. Arias, L.E., Olvera, L.I., Pámanes, J.A., Núñez, J.V.: Patrón de marcha 3D de tipo cicloidal para humanoides y su aplicación al robot Bioloid. Rev. Iberoam. Ing. Mecánica. 18, 3 (2014) 